\title{
Specific effect of the infusion of glucose on blood volume during haemodialysis
}

\author{
Robert W. Nette, Harmen P. Krepel, Anton H. van den Meiracker, \\ Willem Weimar and Robert Zietse \\ Department of Internal Medicine, University Hospital Rotterdam-Dijkzigt, Rotterdam, The Netherlands
}

\begin{abstract}
Background. Intradialytic morbid events such as hypotension and cramps during haemodialysis are generally treated by infusion of iso- or hypertonic solutions. However, differences may exist between solutions with respect to plasma refilling and vascular reactivity.

Methods. We compared the effect of no infusion (NI) with isovolumetric infusion of isotonic saline $0.9 \%$ (IS), saline 3\% (HS), isotonic glucose 5\% (IG), glucose $20 \%(\mathrm{HG})$ and mannitol $20 \%(\mathrm{HM})$, in six patients during the first hour of six standardized haemodialysis sessions with ultrafiltration. Relative blood volume was monitored continuously by measurement of the intravascular amount of protein. Blood pressure was measured by an oscillometric method, while cardiac output was measured by a thoracic impedance technique.

Results. At baseline, no differences in serum urea, sodium, potassium, glucose and osmolarity were found between the various infusion experiments. The maximum increase in relative blood volume directly after infusion was significantly greater with $\mathrm{HG}(5.1 \pm 0.7 \%)$ than with all other infusions $(P<0.05)$. Stroke volume increased $(21.0 \pm 19.2 \%, P<0.05)$ and total peripheral resistance decreased significantly $(15.4 \pm 16.4 \%$, $P<0.05)$ after $\mathrm{HG}$ infusions.

Conclusions. Infusion of hypertonic glucose during dialysis results in a greater increase in relative blood volume (RBV) than equal volumes of other solutions. As mannitol has the same osmolarity, molecule mass and charge, the greater increase in RBV following hypertonic glucose appears to be a specific effect, possibly related to a decline in vascular tone. It is therefore uncertain whether the observed increase in plasma volume during hypertonic glucose infusions will be of clinical benefit.
\end{abstract}

Correspondence and offprint requests to: Robert Nette, University Hospital Rotterdam, Dijkzigt, Department of Internal Medicine, Room D-406, Dr Molewaterplein 403015 GD Rotterdam, The Netherlands. Email: zietse@inw1.azr.nl
Keywords: intradialytic morbid events; relative blood volume; vascular reactivity

\section{Introduction}

Haemodialysis is frequently accompanied by acute symptoms or complications, such as hypotension, severe muscle cramps, dizziness and lightheadedness [1]. An important contributing factor for these intradialytic morbid events (IME) is hypovolaemia due to removal of fluid from the intravascular space by ultrafiltration and inadequate refilling from the extravascular compartment [2]. Inadequate constriction of both arterial and venous vascular beds may also be of importance in the pathogenesis of IME, especially during hypotension [3]. Infusion of fluids to increase blood volume has been advocated to prevent IME. Increasing plasma osmolarity during dialysis has also been shown to reduce IME [4]. The reduction of symptoms may result from improved refill of the intravascular compartment by the induction of an osmotic gradient between the vascular and the extravascular compartment [4,5], but may also be related to a direct effect of osmolarity on cardiovascular reactivity [6]. In clinical practice, isotonic saline $(0.9 \%)$ or hypertonic $(3 \%)$ saline infusions are most frequently used in order to prevent IME. However, increasing the sodium load during dialysis has been shown to increase interdialytic thirst and weight gain [7]. Alternatively, glucose or mannitol solutions can be given. The acute and specific effects of these solutions and their osmolarities on vascular refilling and reactivity are largely unknown. Clear insight into the exact effects of the solutions on haemodynamics and osmolarity is pivotal for the determination of which solution should be given during dialysis-associated morbidity. We therefore compared the effects of saline $0.9 \%$ and $3 \%$, glucose $5 \%$ and $20 \%$, and mannitol $20 \%$ on vascular refilling and vascular reactivity during combined haemodialysis 
and ultrafiltration (HD+UF). In order to obtain optimal reproducibility, the dialysis sessions as well as the infusions were standardized. Moreover, the infusions were given during the first hour of the treatment, when variability in blood volume decrement between dialysis sessions is relatively low [8].

\section{Subjects and methods}

\section{Patients}

Six clinically stable patients, three men and three women, requiring chronic haemodialysis were studied. The patients had a mean age of $48 \pm 5.9$ years and time on haemodialysis averaged $18.5 \pm 12.5$ months. Renal failure resulted from polycystic kidney disease (two), nephrosclerosis (two), renal artery stenosis (one) and antiglomerular basement membrane nephritis (one). Exclusion criteria were acute infectious diseases, diabetes, severe coronary or valvular heart disease and compromised left ventricular function. The patients did not use antihypertensive drugs, except for one patient who used nifedipine. This drug was stopped 1 week prior to entry in the study. The local ethics committee approved the study and informed consent was obtained from each patient. Dry weight was considered when patients remained without symptoms of dyspnoea or oedema during the interdialytic period. Moreover, inferior caval vein diameter (VCD) measurements were performed at 3-week intervals. Overhydration was defined as a VCD of $>11.4 \mathrm{~mm} / \mathrm{m}^{2}$ body surface area, and underhydration was defined as a VCD of $<8 \mathrm{~mm} / \mathrm{m}^{2}$ body surface area [9].

\section{Dialysis prescription}

Dialysis was performed three times a week with the procedure normally used at our institution, using bicarbonate dialysate $(32 \mathrm{mEq} / \mathrm{l})$. Dialysate also contained sodium $138 \mathrm{mmol} / 1$, potassium $2 \mathrm{mmol} / 1$, calcium $1.75 \mathrm{mmol} / 1$, glucose $5.5 \mathrm{mmol} / \mathrm{l}$, with a total osmolarity of $292 \mathrm{mOsmol} / 1$, a conductivity of $11.7 \mathrm{mS} / \mathrm{cm}$ (Fresenius SK-F213; Fresenius AG, Bad Homburg, Germany) and a temperature of $37^{\circ} \mathrm{C}$. Fresenius F-60 high flux dialysers and Fresenius 4008E haemodialysis monitors were used to perform the treatments. Blood and dialysate flow rates were $200-300 \mathrm{ml} / \mathrm{min}$ and $500 \mathrm{ml} / \mathrm{min}$, respectively. Delivered $K_{\mathrm{t}} / \mathrm{V}$ ranged between 1.1 and 1.3, including residual renal function. Patients were connected to the circuit after the priming volume of saline was discarded.

\section{Study protocol}

All sessions were performed on the same day of the week for 6 consecutive weeks. The patients remained supine throughout the experiments and no food or beverages were provided. The investigations were performed during the first hour of six haemodialysis sessions. The ultrafiltration rate was standardized at $20 \mathrm{ml} / \mathrm{kg} / \mathrm{h}$. The study was started after the patients had had a supine rest for $30 \mathrm{~min}$, after which the needles were inserted $(t=0)$. After exactly $10 \mathrm{~min}$ of UF, one of the test solutions was infused by an infusion pump for $10 \min (t=10$ to $t=20)$ at the same rate as the ultrafiltration rate $(20 \mathrm{ml} / \mathrm{kg} / \mathrm{h})$, so that no net fluid was extracted from the body during the infusion period. In each patient, the effects of no infusion (NI), isotonic saline $0.9 \%$ (IS), hypertonic saline 3\% (HS), isotonic glucose 5\% (IG), hypertonic glucose $20 \%$ (HG) and mannitol 20\% (HM) (Baxter BV, Utrecht, The Netherlands) were compared. The order in which the solutions were infused was random. The osmolarity of HS ( $900 \mathrm{mOsmol} / \mathrm{l}$ ) was roughly comparable to the $\mathrm{HM}$ and $\mathrm{HG}$ solutions. The HM and $\mathrm{HG}$ solutions were iso-osmolar (both $1098 \mathrm{mOsmol} / \mathrm{l}$ ).

\section{Measurements}

Relative blood volume (RBV) was measured by means of a blood volume monitor (BVM; Fresenius AG), which measures the total protein concentration, the sum of haemoglobin and plasma proteins in the vascular space. Changes in total protein concentration during dialysis are used to estimate changes in plasma volume. This method has a very good agreement with a standard reference method involving calculation of RBV from serial measurements of haemoglobin levels (standard deviation 1.7\%,r>0.96), and allows precise and reliable measurement of RBV [10]. Moreover, these measurements showed no sensitivity to changes in blood components such as sodium and glucose. Systolic, diastolic and mean arterial blood pressures (SAP, DAP, MAP) and heart rate (HR) were measured in triplicate at 10-min intervals by means of an oscillometric device (Accutor 3; Datascope Co., Paramus, NJ, USA). The average of three consecutive measurements was used for analysis. Stroke volume (SV) was measured every 10 min using electrical impedance cardiography (Cardioscreen Medis, Ilmenau, Germany). Impedance cardiography is based on the fact that when blood is pumped into the aorta from the electrically well isolated heart, the electrical impedance of the thorax changes. SV can subsequently be calculated on the basis of this pulse synchronous change in impedance. This method has proven to give reliable information about the changes in stroke volume during haemodialysis [11]. Moreover, the results of impedance cardiography are highly reproducible (standard deviation $0.36 \mathrm{l} / \mathrm{min}$ ) [12]. One pair of electrodes was placed on each side of the neck. A third and fourth pair were placed on the lateral thorax at the xiphisternal level. Of each pair, one electrode was placed exactly $5 \mathrm{~cm}$ above the other. The upper neck and lower xiphisternal electrodes were stimulated by a $60 \mathrm{kHz}$ sinusoidal current and the resulting voltage was monitored from the inner recording electrodes. Two separate electrodes were placed in order to obtain the electrocardiogram (ECG) signal. Stroke volume was calculated according to the equation of Bernstein [13]:

$\mathrm{SV}=\mathrm{VEPT} \times \operatorname{LVET} \times\left(\mathrm{dZ} / \mathrm{dt}_{\max }\right) /$ TFI $(\mathrm{ml})$,

where VEPT is the volume of electrically participating tissue, which depends on the height and weight of the patient. The weight of the patient at the moment of measurement was considered the predialysis weight minus the weight of the net ultrafiltration volume. LVET is the left ventricular ejection time $(\mathrm{ms}), \mathrm{dZ} / \mathrm{dt}_{\max }(\Omega / \mathrm{ms})$ is the magnitude of the peak value of the impedance derivative and TFI $(\Omega)$ is the thoracic fluid index, which is given by the basic impedance. At 10-min intervals the patients were asked to keep perfectly still, and during 20 heart cycles in the course of the examination the impedance curves were transported into a cardioscreen trend software package (version 3.1) and recorded on a PC screen. A mean impedance curve was calculated by the software program and the curves that varied $>5 \%$ from average were discarded 
manually. When no more than five curves were discarded, stroke volume was calculated from the remaining heart cycles. Total peripheral resistance (TPR) was calculated from SV, HR and MAP using the following formula: $\mathrm{TPR}=(\mathrm{MAP} /(\mathrm{SV} \times \mathrm{HR})) \times 80 \quad\left(\mathrm{dyn} / \mathrm{s} / \mathrm{cm}^{-5}\right)$. Before $(t=0)$ and after $1 \mathrm{~h}$ of treatment $(t=60)$, blood samples were taken for the determination of urea, sodium, potassium, glucose and osmolarity.

Sodium concentration was measured by ionometry. Osmolarity was measured by determining the crystallizing temperature of the sample by freezing point depression, then by using the temperature and calibration curve to determine the osmotic pressure.

\section{Statistical analysis}

All data and values are presented as mean \pm standard deviation.

Differences in body weight, haemodynamic parameters and laboratory between the procedures were analysed by one way analysis of variance (ANOVA) with the post hoc LSD test using the SPSS statistical software package (SPSS version 8.0). Changes in haemodynamic and laboratory parameters compared with baseline were analysed with a paired $t$-test.

\section{Results}

\section{Body weight}

The average dry weight was $53.8 \pm 13.5 \mathrm{~kg}$, while the mean interdialytic weight gain was $4.6 \pm 2.0 \%$ of body weight (Table 1). During the 6-week period, dry weight remained stable in all patients. The average interdialytic weight gain was comparable for all infusion experiments. However, patients 2 and 3 showed an intra-individual variability in interdialytic weight gain.

\section{Relative blood volume}

During ultrafiltration, at a rate of $20 \mathrm{ml} / \mathrm{kg} / \mathrm{h}, \mathrm{RBV}$ fell by $0.13 \%$ in the first $10 \mathrm{~min}$ in all patients (Figure 1). A 10-min infusion at a rate equal to the rate of ultrafiltration prevented a further decrease in RBV, as RBV at the end of the infusion $(t=20)$ was significantly different from the control experiment for all solutions infused (Table 2). With infusion of
HG the increase in RBV was significantly greater than the increase observed with all other infusions (Figure 1, Table 2). Moreover, the time at which RBV reached the same level as the level at which the infusion was started was $18 \pm 2$ min for $\mathrm{HG}$, which was significantly longer than all other infusion experiments $(P<0.05$; Figure 1$)$. In patient 2 , the interdialytic weight gain during the $\mathrm{HG}$ and $\mathrm{HS}$ infusion session were comparable and RBV increased by $4.8 \%$ during the HG infusions, whereas RBV increased only $1.8 \%$ during the HS infusions (from $t=10$ to $t=20 \mathrm{~min}$ ). Moreover, RBV increased only by $2.3 \%$ during the HM session, despite the fact that interdialytic weight gain was relatively low. The interdialytic weight gain for patient 3 during the $\mathrm{HG}$ and $\mathrm{HM}$ sessions were comparable. During the HG infusions the increase in blood volume was larger than during the HM infusion ( $4.1 \%$ by $\mathrm{HG}$ and $2.3 \%$ during $\mathrm{HM}$ ).

\section{Blood pressure, heart rate and stroke volume}

Blood pressure and heart rate remained unchanged during all experiments (Table 3). No IME events were noted. After infusion of $\mathrm{HG}$, blood pressure tended to increase but these changes did not show statistical significance. No episodes of symptomatic hypotension were noted. Stroke volume increased and TPR decreased significantly after the HG infusion.

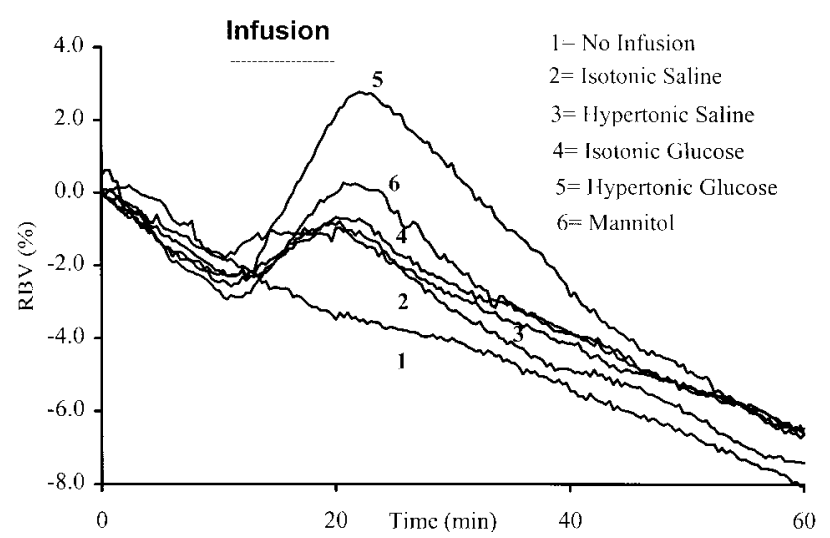

Fig. 1. Mean changes in relative blood volume $(\%)$ for all patients during combined dialysis and ultrafiltration $(20 \mathrm{ml} / \mathrm{kg} / \mathrm{h})$ following the infusion of different solutions. The increase in RBV is significantly greater during infusion of hypertonic glucose (5).

Table 1. Dry weight and interdialytic weight gain

\begin{tabular}{|c|c|c|c|c|c|c|c|}
\hline Patient & Dry weight $(\mathrm{kg})$ & NI $(\%)$ & IS $(\%)$ & HS (\%) & IG $(\%)$ & HG (\%) & HM (\%) \\
\hline 1 & 56.5 & 6.9 & 7.6 & 6.4 & 6.7 & 6.5 & 8.4 \\
\hline 2 & 32.0 & 2.5 & 4.1 & 8.4 & 6.2 & 7.1 & 4.7 \\
\hline 3 & 70.0 & 3.8 & 3.3 & 3.2 & 1.6 & 1.7 & 1.6 \\
\hline 4 & 49.5 & 4.8 & 3.2 & 4.6 & 3.6 & 4.4 & 3.6 \\
\hline 5 & 65.5 & 2.4 & 2.9 & 2.4 & 3.5 & 2.7 & 2.1 \\
\hline 6 & 49.5 & 6.6 & 6.5 & 5.6 & 6.6 & 4.2 & 6.5 \\
\hline Mean \pm SD & $53.8 \pm 13.5$ & $4.5 \pm 1.9$ & $4.6 \pm 1.9$ & $5.1 \pm 2.1$ & $4.7 \pm 2.1$ & $4.4 \pm 2.1$ & $4.5 \pm 2.6$ \\
\hline
\end{tabular}

All means are not significant. 
Table 2. Changes in relative blood volume $(\Delta \mathrm{RBV})$ compared with the start of the infusion $(t=10 \mathrm{~min})$

\begin{tabular}{|c|c|c|c|c|c|}
\hline & $\begin{array}{l}\Delta \mathrm{RBV}(\%) \\
t=20 \mathrm{~min}\end{array}$ & $\begin{array}{l}\Delta \mathrm{RBV}(\%) \\
t=30 \mathrm{~min}\end{array}$ & $\begin{array}{l}\Delta \mathrm{RBV}(\%) \\
t=40 \mathrm{~min}\end{array}$ & $\begin{array}{l}\Delta \mathrm{RBV}(\%) \\
t=50 \mathrm{~min}\end{array}$ & $\begin{array}{l}\Delta \mathrm{RBV}(\%) \\
t=60 \mathrm{~min}\end{array}$ \\
\hline No infusion & $-1.5 \pm 0.8^{\mathrm{a}}$ & $-1.9 \pm 1.1$ & $-3.4 \pm 1.9$ & $-4.6 \pm 2.3$ & $-6.0 \pm 2.3$ \\
\hline Isotonic saline $(0.9 \%)$ & $0.5 \pm 1.0$ & $-1.1 \pm 1.4$ & $-2.4 \pm 2.0$ & $-3.6 \pm 2.4$ & $-4.9 \pm 2.7$ \\
\hline Hypertonic saline $(3 \%)$ & $1.5 \pm 0.8^{\mathrm{b}}$ & $-0.8 \pm 2.3$ & $-2.4 \pm 1.2$ & $-3.6 \pm 1.2$ & $-5.0 \pm 2.2$ \\
\hline Isotonic glucose $(5 \%)$ & $1.6 \pm 1.0^{\mathrm{b}}$ & $-0.3 \pm 2.4$ & $-1.8 \pm 3.5$ & $-3.3 \pm 3.9$ & $-4.3 \pm 4.7$ \\
\hline Hypertonic glucose $(20 \%)$ & $4.6 \pm 0.6^{\mathrm{a}, \mathrm{b}}$ & $2.6 \pm 1.4^{\mathrm{a}, \mathrm{b}}$ & $-0.7 \pm 2.2$ & $-2.7 \pm 1.6$ & $-4.6 \pm 3.8$ \\
\hline Hypertonic mannitol $(20 \%)$ & $2.6 \pm 1.2^{\mathrm{b}}$ & $0.8 \pm 1.9$ & $-1.1 \pm 1.9$ & $-2.6 \pm 2.6$ & $-3.8 \pm 3.1$ \\
\hline
\end{tabular}

All values are given as mean \pm standard deviation.

${ }^{\mathrm{a}} P<0.05$ compared with all other infusions; ${ }^{\mathrm{b}} P<0.05$ compared with baseline.

Table 3. Changes in systolic arterial pressure, heart rate, stroke volume and total peripheral resistance between the beginning $(t=10)$ and end $(t=20)$ of the infusion period

\begin{tabular}{lcrrr}
\hline & $\Delta$ SAP $(\%)$ & $\Delta$ HR $(\%)$ & $\Delta$ SV $(\%)$ & $\Delta$ TPR $(\%)$ \\
\hline No infusion & $-0.3 \pm 5.0$ & $+2.2 \pm 5.6$ & $-6.8 \pm 10.6$ & $+9.7 \pm 12.6$ \\
Isotonic saline $(0.9 \%)$ & $-1.0 \pm 3.6$ & $-1.6 \pm 3.7$ & $+4.2 \pm 13.4$ & $-1.4 \pm 14.6$ \\
Hypertonic saline $(3 \%)$ & $-0.5 \pm 4.8$ & $0.0 \pm 2.3$ & $+6.0 \pm 23.6$ & $0.0 \pm 27.0$ \\
Isotonic glucose $(5 \%)$ & $-1.0 \pm 8.1$ & $+3.0 \pm 5.0$ & $+6.9 \pm 18.4$ & $-1.2 \pm 18.2$ \\
Hypertonic glucose $(20 \%)$ & $+7.4 \pm 10.8$ & $0.4 \pm 5.4$ & $+21.0 \pm 19.2^{\mathrm{a}, \mathrm{b}}$ & $-15.4 \pm 16.4^{\mathrm{a}, \mathrm{b}}$ \\
Hypertonic mannitol $(20 \%)$ & $+1.3 \pm 4.5$ & $-3.8 \pm 4.1$ & $+9.3 \pm 18.0$ & $-6.1 \pm 17.6$ \\
\hline
\end{tabular}

${ }^{\mathrm{a}} P<0.05$ compared with baseline; ${ }^{\mathrm{b}} P<0.05$ compared with no infusions.

$\Delta \mathrm{SAP}$, systolic arterial pressure; $\Delta \mathrm{HR}$, heat rate; $\Delta \mathrm{SV}$, stroke volume; $\Delta \mathrm{TPR}$, total peripheral resistance.

All values are given as mean \pm SD.

Table 4. Changes in laboratory parameters between the start of the dialysis session $(t=0)$ and $1 \mathrm{~h}$ of dialysis $(t=60)$

\begin{tabular}{lccccc}
\hline & $\begin{array}{l}\Delta \text { Urea } \\
(\mathrm{mmol} / \mathrm{l})\end{array}$ & $\begin{array}{l}\Delta \mathrm{Na}^{+} \\
(\mathrm{mmol} / \mathrm{l})\end{array}$ & $\begin{array}{l}\Delta \mathrm{K}^{+} \\
(\mathrm{mmol} / \mathrm{l})\end{array}$ & $\begin{array}{l}\Delta \mathrm{Glucose} \\
(\mathrm{mmol} / \mathrm{l})\end{array}$ & $\begin{array}{l}\Delta \text { Osmol } \\
(\mathrm{mosmol} / \mathrm{l})\end{array}$ \\
\hline No infusion & $-11.9 \pm 6.5^{\mathrm{a}}$ & $2.5 \pm 3.2$ & $-0.85 \pm 0.29^{\mathrm{a}}$ & $-1.35 \pm 2.02$ & $-10.4 \pm 5.8^{\mathrm{a}}$ \\
Isotonic saline $(0.9 \%)$ & $-11.5 \pm 7.9^{\mathrm{a}}$ & $2.8 \pm 4.8$ & $-0.83 \pm 0.41^{\mathrm{a}}$ & $-1.12 \pm 1.31$ & $-3.8 \pm 9.5$ \\
Hypertonic saline $(3 \%)$ & $-11.0 \pm 5.3^{\mathrm{a}}$ & $3.0 \pm 1.1^{\mathrm{a}}$ & $-0.95 \pm 0.11^{\mathrm{a}}$ & $-1.07 \pm 0.83^{\mathrm{a}}$ & $-5.8 \pm 7.0$ \\
Isotonic glucose $(5 \%)$ & $-9.4 \pm 2.4^{\mathrm{a}}$ & $1.3 \pm 2.0$ & $-0.98 \pm 0.26^{\mathrm{a}}$ & $-0.13 \pm 1.18^{\mathrm{b}}$ & $-8.2 \pm 7.2^{\mathrm{a}}$ \\
Hypertonic glucose $(20 \%)$ & $-10.1 \pm 3.4^{\mathrm{a}}$ & $0.5 \pm 1.8$ & $-1.30 \pm 0.57^{\mathrm{a}, \mathrm{b}, \mathrm{c}, \mathrm{e}}$ & $1.93 \pm 1.22^{\mathrm{a}, \mathrm{f}}$ & $-6.9 \pm 7.4$ \\
Hypertonic mannitol $(20 \%)$ & $-7.7 \pm 1.4^{\mathrm{a}}$ & $-1.2 \pm 1.5^{\mathrm{b}, \mathrm{c}, \mathrm{d}}$ & $-0.86 \pm 0.40^{\mathrm{a}}$ & $-0.17 \pm 1.18$ & $-2.2 \pm 5.0$ \\
\hline
\end{tabular}

All values are given as mean $\pm \mathrm{SD}$. ${ }^{\mathrm{a}} P<0.05$ compared with baseline; ${ }^{\mathrm{b}} P<0.05$ compared with no infusions; ${ }^{\mathrm{c}} P<0.05$ compared with isotonic saline; ${ }^{\mathrm{d}} P<0.05$ compared with hypertonic saline; ${ }^{\mathrm{e}} P<0.05$ compared with mannitol; ${ }^{\mathrm{f}} P<0.05$ compared with all other infusions.

\section{Laboratory parameters}

At baseline no differences in serum urea, glucose, sodium, potassium and osmolarity were found between the various infusion experiments $(27.9 \pm 6.8 \mathrm{mmol} / \mathrm{l}$, $6.7 \pm 1.7 \mathrm{mmol} / 1, \quad 137 \pm 2.9 \mathrm{mEq} / 1, \quad 5.37 \pm 0.72 \mathrm{mEq} / 1$ and $307 \pm 8 \mathrm{mOsmol} / \mathrm{l}$, respectively). After $1 \mathrm{~h}$ of dialysis, serum urea concentration was decreased by a similar extent in all experiments (Table 4). Not surprisingly, serum sodium increased significantly after HS (from $137 \pm 2.9$ to $140.3 \pm 3.0 \mathrm{mEq} / 1 ; P<0.05$ ) and sodium decreased after the HM compared with most other solutes $(136 \pm 2.5$ to $135 \pm 2.0 \mathrm{mEq} / \mathrm{l})$. Serum potassium was lowered significantly during all experiments. The decrease was significantly greater after HG compared with NI, HM and IS experiments $(5.4 \pm 0.7$ to $4.1 \pm 0.6 \mathrm{mEq} / 1 ; \quad P<0.05)$. Glucose increased significantly after $\mathrm{HG}$ infusion only
$(6.3 \pm 0.9$ to $8.2 \pm 1.2 \mathrm{mmol} / 1 ; P<0.05)$. Plasma osmolarity decreased during NI and IG, and tended to decrease in all infusion experiments, but this decrease did not reach statistical significance.

\section{Discussion}

The results of our study demonstrate that during haemodialysis with ultrafiltration, infusion of hypertonic glucose solution $(20 \%)$ results in a greater preservation of RBV than isovolumetric infusions of either normotonic or hypertonic saline or mannitol. Compared with the other infusion experiments, the increased RBV during hypertonic glucose infusion was associated with an increase in stroke volume and a 
decrease in vascular resistance. In our study, the finding that infusion of hypertonic glucose is more effective in increasing RBV than infusion of mannitol $20 \%$ is remarkable. Van der Sande et al. [14] compared colloids, such as albumin and or hydroxyethylstarch (HES) with saline and found a much greater increase in blood volume and blood pressure after the infusion of colloids. These differences were attributed to an increase in oncotic pressure during the colloid infusions. However, comparing the osmotic agents used in our study, mannitol closely resembles glucose in that it has the same molecular mass and charge, and neither solution increases the oncotic pressure. Unlike glucose, which is rapidly transported from the extracellular to the intracellular space by insulin, mannitol is slowly eliminated from plasma $[15,16]$. Thus, compared with infusion of mannitol, infusion of glucose is associated with a shorter lasting increase in plasma osmolarity. Indeed, in the present study, osmolarity, $40 \mathrm{~min}$ after infusions were discontinued, tended to be slightly higher after administration of mannitol than after administration of glucose. As changes in osmolarity, and therefore oncotic pressure, do not provide an explanation for the greater increase in RBV after infusion of hypertonic glucose, it is tempting to speculate that glucose-induced vasodilatation accounts for the observed increase in RBV. Compared with other infusions or no infusion at all, infusion of hypertonic glucose was associated with a vasodilator response reflected by a decrease in vascular resistance and an increase in stroke volume. One could argue that the changes in electrolyte composition of the plasma induced by the sudden infusion of hypertonic salt or water directly affect impedance and might cause errors in the estimation of stroke volume and the subsequent calculation of vascular resistance. However, this change will not alter the magnitude of the peak value, as a correction for the baseline impedance is made. Therefore we do not expect problems with the adequacy of the impedance cardiography. Moreover, hypertonic glucose infusion will give a much higher electrical resistance than the infusion of hypertonic saline, which is an electrically active compound. As electrical resistance is inversely related to impedance and stroke volume, changes in stroke volume during hypertonic glucose infusion would be underestimated and those during saline would be overestimated. It has been shown that infusion of hypertonic glucose, but not of normotonic glucose or hypertonic mannitol into the brachial artery, is associated with a forearm vasodilator response [17]. A study using vasodilator agents demonstrated that vasodilatation is associated with an increase in plasma volume without a concomitant increase in body weight, indicating that redistribution of the extracellular volume between the intravascular and extravascular compartments underlies this increase in plasma volume [18]. Recruitment of capillaries leading to an expansion of the vascular area could explain the vasodilatation-induced increase in RBV. Such a mechanism would be especially favourable for the action of glucose, as it can increase the disposal of glucose to the intracellular compartment [19].

It is uncertain whether the observed increase in RBV is of clinical benefit, as a change in peripheral resistance could induce a change in the critical value of blood volume at which IME occurs. The relatively small increase in blood volume during hypertonic sodium infusion could therefore lead to a more effective RBV and cardiac filling pressure. Previous studies showed that hypertonic saline infusion during hypotension is effective in raising blood pressure and cardiac filling pressure [5,6]. A dissociation between blood volume and vascular tone would also change the algorithms for those clinical settings in which RBV measurements are performed with a feedback control in order to prevent IME.

We conclude that infusion of hypertonic glucose during dialysis results in a greater increase in RBV than equal volumes of other solutions. As mannitol has the same osmolarity, molecule mass and charge, the greater increase in RBV following hypertonic glucose appears to be a specific effect, possibly related to a decline in vascular tone. It is therefore uncertain whether the observed increase in RBV will be of clinical benefit during IME.

Acknowledgements. This study was presented as a poster presentation at the 32nd scientific meeting of the ASN in Miami in 1999.

\section{References}

1. Daugirdas JT. Dialysis hypotension: a hemodynamic analysis. Kidney Int 1991; 39: 233-246

2. Steuer RR, Leypoldt JK, Cheung AK, Harris DH, Conis JM. Hematocrit as an indicator of blood volume and a predictor of intradialytic morbid events. ASAIO J 1994; 40: M691-M696

3. Kooman JP, Gladziwa U, Böcker G, van Bortel LMAB, van Hooff JP, Leunissen KML. Role of the venous system in hemodynamics during ultrafiltration and bicarbonate dialysis. Kidney Int 1992; 42: 718-726

4. Kouw PM, Olthof CG, Gruteke P et al. Influence of high and low sodium dialysis on blood volume preservation. Nephrol Dial Transplant 1991; 6: 876-880

5. Kinet JP, Balland N, Soyeur D, Collignon P, Godon JP. Pathophysiology and treatment of acute hypotension occurring during hemodialysis. Néphrologie 1981; 2: 77-80

6. Gong R, Lindberg J, Abrams J, Whitaker WR, Wade CE, Gouge S. Comparison of hypertonic saline solutions and dextran in dialysis induced hypotension. J Am Soc Nephrol 1993; 3: $1808-1812$

7. Wilkinson R, Barber SG, Robson V. Cramps, thirst and hypertension in hemodialysis patients. The influence of dialyzate sodium concentration. Clin Nephrol 1977; 7: 101-110

8. Krepel HP, Nette RW, Akçahüseyin E, Weimar W, Zietse R. Variability of relative blood volume during hemodialysis. Nephrol Dial Transplant 2000; 15: 673-679

9. Cherieux EC, Leunissen KML, Kouw P et al. New techniques to determine fluid status in hemodialyzed patients. Kidney Int 1993; 43 [Suppl 41]: S50-S56

10. Johner C, Chamney PW, Schneditz D, Kramer M. Evaluation of an ultrasonic blood volume monitor. Nephrol Dial Transplant 1998; 13: 2098-2103

11. Handt A, Farber MO, Szwed JJ. Intradialytic measurement of cardiac output by thermodilution and impedance cardiography. Clin Nephrol 1977; 7: 61-64 
12. Mehlsen J, Bonde J, Stadeager C, Rehling M, Tango M, Trap Jensen J. Reliability of impedance cardiography in measuring central hemodynamics. Clin Physiol 1991; 11: 579-588

13. Bernstein DP. A new stroke volume equation for thoracic electrical bioimpedance: Theory and rationale. Crit Care Med 1986; 14: 904-909

14. Van der Sande FM, Kooman JP, Barendregt JNM, Nieman FHM, Leunissen KML. Effect of intravenous saline, albumin or hydroxyethylstarch on blood volume during combined ultrafiltration and hemodialysis. J Am Soc Nephrol 1999; 10: 1303-1308

15. Nau R. Osmotherapy for elevated intracranial pressure: a critical reappraisal. Clin Pharmacokinet 2000; 38: 23-40
16. Khalaf AN, Kerp L, Petersen KG. Osmotic stress due to changes in plasma glucose and its regulation in IDDM. Horm Metab Res 1992; 24: 375-378

17. Van Veen S, Frölich M, Chang PC. Acute hyperglycemia in the forearm induces vasodilatation that is not modified by hyperinsulinemia. J Hum Hypertens 1999; 13: $263-268$

18. Wysocki M, Andersson OK, Persson B, Bagge U, Braide M. Hemorheologic effects of vasodilatation in essential hypertension. Angiology 1996; 42: 869-878

19. Baron AD, Steinberg H, Brechtel G, Johnson A. Skeletal muscle blood flow independently modulates insulin-mediated glucose uptake. Am J Physiol 1994; 266: E248-E253

Received for publication: 14.4 .01

Accepted in revised form: 14.2 .02 